\title{
Differentiating white matter measures that protect against vs. predispose to bipolar disorder and other psychopathology in at-risk youth
}

Renata Rozovsky (iD ${ }^{1 凶}$, Amelia Versace (iD) ${ }^{1,2}$, Lisa K. Bonar ${ }^{1}$, Michele Bertocci (iD ${ }^{1}$, Cecile D. Ladouceur (D) ${ }^{1}$, Jay Fournier (iD ${ }^{1}$, Kelly Monk ${ }^{1}$, Halimah Abdul-waalee ${ }^{1}$, Genna Bebko ${ }^{1}$, Danella Hafeman ${ }^{1}$, Dara Sakolsky $\mathbb{D}^{1}$, Tina Goldstein ${ }^{1}$, Boris Birmaher ${ }^{1}$ and Mary L. Phillips $\mathbb{D}^{1}$

(c) The Author(s) 2021

Bipolar disorder (BD) is highly heritable. Identifying objective biomarkers reflecting pathophysiological processes predisposing to, versus protecting against $B D$, can help identify $B D$ risk in offspring of $B D$ parents. We recruited $21 \mathrm{BD}$ participants with a first-degree relative with $B D, 25$ offspring of $B D$ parents, 27 offspring of comparison parents with non-BD psychiatric disorders, and 32 healthy offspring of healthy parents. In at-risk groups, 23 had non-BD diagnoses and 29, no Axis-I diagnoses(healthy). Five at-risk offspring who developed BD post scan(Converters) were included. Diffusion imaging(dMRI) analysis with tract segmentation identified between-group differences in the microstructure of prefrontal tracts supporting emotional regulation relevant to BD: forceps minor, anterior thalamic radiation(ATR), cingulum bundle(CB), and uncinate fasciculus(UF). BD participants showed lower fractional anisotropy (FA) in the right CB (anterior portion) than other groups $(q<0.05)$; and in bilateral ATR (posterior portion) versus at-risk groups $(q<0.001)$. Healthy, but not non-BD, at-risk participants showed significantly higher FA in bilateral ATR clusters than healthy controls $(q s<0.05)$. At-risk groups showed higher FA in these clusters than BD participants $(q s<0.05)$. Non-BD versus healthy at-risk participants, and Converters versus offspring of BD parents, showed lower FA in the right ATR cluster $(q 5<0.05)$. Low anterior right CB FA in BD participants versus other groups might result from having BD. High bilateral ATR FA in at-risk groups, and in healthy atrisk participants, versus healthy controls might protect against BD/other psychiatric disorders. Absence of elevated right ATR FA in non-BD versus healthy at-risk participants, and in Converters versus non-converter offspring of BD parents, might lower protection against $\mathrm{BD}$ in at-risk groups.

Neuropsychopharmacology (2021) 46:2207-2216; https://doi.org/10.1038/s41386-021-01088-1

\section{INTRODUCTION}

Bipolar Disorder (BD) is one of the most debilitating psychiatric illnesses, affecting $1-3 \%$ of the adult population worldwide. BD commonly occurs in adolescence or early adulthood, and causes emotional and behavioral problems often leading to poor psychosocial function, substance abuse and suicide [1-3]. BD is highly heritable [4-7]. Unfortunately, BD is frequently misdiagnosed or diagnosed late [8]. Therefore, earlier identification of future BD risk is a key research priority in BD [9]. The longitudinal Bipolar Offspring Study (BIOS) [10], which examines the development of psychiatric symptomatology in offspring of Bipolar parents (OBP), and other studies reported rates of $B D$ in OBP ranging from 15 to $20 \%$ [11-13]. In addition, in offspring of parents with early-onset $\mathrm{BD}$, the risk increases to $30-50 \%$ $[5,14,15]$. Thus, pediatric populations, and especially OBP, are appropriate populations in which to examine factors associated with future BD risk.

Identifying objective biomarkers that reflect pathophysiological processes and are not dependent on subjective report is an important step to facilitate earlier and accurate identification of future BD risk. Structural and/or functional abnormalities in neural circuitries important for processes that are aberrant in BD, e.g., emotional regulation and reward processing [16] might be apparent before the onset of symptoms in youth at risk of BD [17]. Thus, neuroimaging studies of OBP are a promising way to identify objective markers of future $B D$ risk in a potentially vulnerable population.

Yet, given that BD-parents often show high rates of comorbid psychopathology (e.g., depression, ADHD), OBP are at increased risk not only for $\mathrm{BD}$ but also for other psychopathology, especially depression, ADHD, anxiety, and substance abuse $[10,18,19]$. As a result, it is difficult for neuroimaging studies of OBP to differentiate neural markers associated with non-BD psychopathology from the more specific markers associated with $B D$ risk in OBP. Other factors that complicate the identification of $B D$ risk factors in OBP are that prodromal symptoms of $B D$, including non-BD disorders, in OBP often overlap with those in offspring at risk of other psychiatric disorders, due to OBP having parents with these other disorders $[20,21]$. Furthermore, living with a parent with any psychiatric disorder also likely affects the offspring's development and general well-being [22-24]. More recent BIOS studies $[25,26]$ have therefore included offspring of comparison

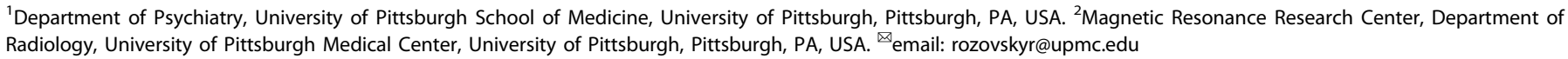

Received: 19 February 2021 Revised: 17 June 2021 Accepted: 24 June 2021

Published online: 20 July 2021 
parents with non-BD psychopathology (OCP) and healthy offspring of healthy parents, to differentiate neuroimaging abnormalities common to OBP and OCP that are more likely to be associated with risk for non-BD disorders from those that are specific to OBP, and thus more likely to be associated with risk for $\mathrm{BD}$. Another difficulty with neuroimaging studies of OBP is that even after including OCP, it remains unclear whether any abnormalities that are specific to OBP reflect risk for future BD or protective markers against the development of $\mathrm{BD}$ and other psychiatric disorders, as no studies of OBP (and OCP) to date included a comparison group of offspring with $\mathrm{BD}$.

White matter (WM) abnormalities are increasingly implicated in the neurobiology of $\mathrm{BD}$ in diffusion imaging (dMRI) studies [27-31]. These abnormalities might result from aberrant maturation [32]. Lower and higher fractional anisotropy (FA), an indirect measure of fiber collinearity in WM tracts, are reported in $\mathrm{BD}$, with abnormalities in adult and pediatric $\mathrm{BD}$ cohorts observed in networks supporting emotional regulation, including the corpus callosum, cingulum bundle (CB), anterior thalamic radiation (ATR), and uncinate fasciculus (UF) [32-50]. Abnormalities in WM in adults and youth at-risk for BD versus healthy controls have also been reported [25, 32, 46, 51-55]. Thus, examining WM in OBP, OCP, OHP and offspring with $\mathrm{BD}$ can help differentiate biomarkers of future BD risk from biomarkers conferring risk for other psychiatric disorders, and from biomarkers conferring protection against future BD and other psychiatric disorders.

To further understanding of BD risk, we therefore recruited four offspring groups: offspring of $B D$ parents with $B D$ themselves $(B D)$, offspring who did not have a BD diagnosis themselves of $B D$ parents or of comparison parents with non-BD psychopathology (OBP and $\mathrm{OCP}$, respectively), and healthy offspring of healthy parents (OHP). This allowed us to: 1. identify abnormalities (relative to OHP) in WM tracts of interest in at-risk offspring (OBP, OCP) that resembled abnormalities in offspring with $\mathrm{BD}$ (i.e., disease biomarkers), and were thus more likely to reflect biomarkers of BD risk versus risk for other psychiatric disorders or biomarkers conferring protection against BD and other psychiatric disorders; and 2. identify abnormalities (relative to OHP) in WM tracts in healthy OBP and OCP versus non-BD OBP and OCP, to help differentiate between biomarkers of protection against, versus risk for, $B D$ and other psychiatric disorders. Additionally, we included five participants (four OBP, one OCP) who developed BD after their neuroimaging assessment. Even if underpowered, the inclusion of this subgroup allowed us to explore which, if any, WM abnormalities in these individuals resembled the abnormalities in BD offspring, as an additional step to elucidate the specific WM abnormalities that might predispose to $\mathrm{BD}$. We also used tractometry [56] to determine whether the main effects of group were focal or across the entire tract.

Given the extant literature in $B D$, we focused on the $A T R, C B$, forceps minor, and UF. We hypothesized that:

1. BD would show abnormally reduced FA in all WM tracts of interest versus other groups, reflecting $B D$ disease biomarkers.

2. OBP and OCP would show abnormally reduced FA in WM tracts showing abnormally reduced $F A$ in $B D$, reflecting $B D$ risk biomarkers; and these abnormalities would be of significantly greater magnitude in OBP than OCP, and in non-BD OBP and OCP versus healthy OBP and OCP.

3. Healthy OBP and OCP would show abnormalities in WM tracts that were not shown by non-BD OBP and $\mathrm{OCP}$, reflecting biomarkers conferring protection against $\mathrm{BD}$ and other psychiatric disorders.

4. In exploratory analyses, FA abnormalities in OBP and OCP that were also common to $\mathrm{BD}, \mathrm{BD}$ risk biomarkers, would be present in the small group of OBP and OCP that converted to BD after the neuroimaging assessment.
Previous findings did not allow us to make hypotheses about the more specific nature of the above patterns of WM abnormalities.

\section{METHODS AND MATERIALS \\ Participants}

121 OBP, OCP, and OHP aged 8-17 years, were recruited from BIOS [8]. BD had a confirmed $\mathrm{BD}$ diagnosis and at least one $1 \mathrm{st} / 2 \mathrm{nd}$ degree relative with a confirmed BD diagnosis (Structured Clinical Interview for DSM-IV (SCID) [57] or Family History questionnaire (Supplementary Materials)). OBP had no BD diagnosis and had at least one parent with a BD diagnosis (SCID). OCP had no BD diagnosis and had at least one parent with a nonBD diagnosis, including Major Depressive Disorder, Attention-Deficit/ Hyperactivity Disorder, and/or an Anxiety Disorder $(n=25)$; or had themselves an Anxiety Disorder or Depressive disorder $(n=2)$. OHP were healthy offspring with no family history (1st degree) of psychiatric illness, other than mild symptoms of anxiety disorders/PTSD in parents $(n=2)$. For exclusion criteria and sensitivity analysis, see Supplementary Materials.

Eleven participants were excluded from analyses due to movement and/ or poor data reconstruction. Based on clinical assessment and interviews with offspring and their parents, the final sample $(n=110)$ included four groups: $\mathrm{BD}$-offspring with $\mathrm{BD}$ of parents with $\mathrm{BD}(n=21$, females/ males $=14 / 7$, mean age $[S D]=13.89$ [2.89]); OBP—offspring without BD of BD parents $(n=25$, females/males $=12 / 13$, mean age [SD] $=13.59$ [2.49], 1 left-handed), OCP -offspring without $\mathrm{BD}$ of parents with non-BD disorders ( $n=27$ females/males $=12 / 15$, mean age $[S D]=13.12$ [2.24], 1 lefthanded), and OHP -healthy offspring of healthy parents $(n=32$, females/males $=14 / 18$, mean age [SD] = 13.19 [2.57], 2 left-handed).

All offspring were clinically assessed every two years after intake. Five offspring (four OBP and one OCP) converted to BD after scan: Converters ( $n=5$, females/males $=2 / 3$, mean age $[S D]=15.05$ [2.57]). The mean time between scan and $B D$ conversion was 3.05 years $(S D=1.64)$. The mean time between the first scan and the latest follow-up for OBP and OCP was 5.2 years $(S D=1.74)$. Before study participation, parents and guardians provided written informed consent, and youth provided written informed assent. The Pittsburgh University IRB approved the study.

\section{Clinical assessment}

Psychiatric diagnoses were confirmed by a licensed psychiatrist or psychologist before the neuroimaging assessment, using the Kiddie Schedule for Affective Disorders and Schizophrenia for School-Age Children (K-SADS) - Present and Lifetime Version [58] for offspring (interrater reliability for K-SADS is 0.80 ), and the Structural Clinical Interview for DSM-IV [59] and Family History Screen [60] for parents. Assessments also included the Screen for Child Anxiety Related Disorders (SCARED) [61, 62], Children's Affective Lability Sale (CALS) [63], Mood and Feelings Questionnaire (MFQ) [64], to assess depressive symptoms, K-SADS Mania Rating Scale (KMRS) [65], and K-SADS Depression Rating Scale (KDRS) [58]. Parent- and child-reported SCARED, CALS, and MFQ were administered on the scan day. K-SADS Mania Rating Scale (KMRS) [65], and K-SADS Depression Rating Scale (KDRS) [58] were administered to parents and offspring on average 2 months before or after the scan, at the alternate yearly assessments: range from 1 to 475 days; Mean $=66.7$ and $\mathrm{SD}=72.8$. Regression analysis revealed no significant effects of K-SADS latency on our main findings (Supplementary Materials).

All participants also completed medication forms that documented psychotropic medications used at the time of the scan. Sixteen BD participants were taking psychotropic medications (stimulants, antipsychotics, antidepressants, benzodiazepines, mood stabilizers). Two OBP participants were taking psychotropic medications for non-BD diagnoses (one was taking a stimulant, and one a non-stimulant). Three OCP were taking psychotropic medications for non-BD diagnoses (two participants were taking antidepressants and one was taking stimulants). Handedness was assessed using the Annett Behavioral Handedness Index [66]. Interviewers also evaluated socioeconomic status (SES) [67].

\section{dMRI data analysis}

For diffusion imaging acquisition, please see Supplementary Materials. Diffusion-weighted images were transferred to a Unix-based workstation. Distortions due to eddy currents and head motion were reduced using eddy correct [68] within the Functional Magnetic Resonance Imaging of the Brain Software Library (FSL; http://www.fmrib.ox.ac.uk/fsl). The gradient 
vectors were rotated accordingly to the spatial transformations applied to their corresponding volumes using fdt_rotate_bvecs within FSL. Skull and non-brain voxels were stripped using the brain extraction tool (bet) [69] within FSL [70]. Tracts were segmented in native space using TractSeg [56], using a convolutional neural network-based approach (Tract Orientation Mapping) to automatically segment 50 major WM tracts using the field of fiber orientation distribution function (fODF), as implemented in mrtrix-3 [71]. TOM facilitates bundle-specific tractography based on a learned mapping from the original fODF peaks to a list of tract orientation maps [72]. TractSeg allows for a point-wise tractographic approach (tractometry). The reconstructing algorithm used was Constrained Spherical Deconvolution. After accurate reconstruction of the tracts, the main dMRI metric of interest, FA, was extracted in 98 nodes along each tract (point-wise values) and averaged across the entire tract (mean values) and exported into SPSS (version 26). Given that other dMRI metrics [73], i.e., radial diffusivity (RD), an indirect measure of fiber dispersion and possibly abnormal myelination, and axial diffusivity (AD), the magnitude of the principal diffusion direction of the fibers, can inform understanding of FA abnormalities, these additional metrics were extracted from clusters showing a main effect of group on FA.

\section{Statistical analysis}

Age [74, 75], sex [76], and IQ [77, 78] on WM, these variables, and handedness, were covariates in all analyses of dMRI measures. To test our hypotheses, a threefold analytic approach was applied. A false discovery rate (FDR; $q<0.05)$ correction [79] was used to account for multiple comparisons in level 2 and 3 analyses below.

\section{Between-group differences in demographic and clinical measures}

Chi-squared tests for sex, handedness, and differences in the proportion of offspring with non-BD diagnoses in each group were performed. To examine differences between groups in age, IQ (assessed by Wechsler Abbreviated Scale of Intelligence [80], SES (socioeconomic status by Hollingshead [67]), SCARED, CALS, MFQ, KMRS, and KDRS, nonparametric Kruskal-Wallis and Dunn's post hoc tests were performed, as appropriate.

\section{Main effect of group on FA in WM tracts of interest}

2.i. Multivariate Analysis of Variance (MANOVA) was first performed to identify the main effect of group (BD, OBP, OCP, OHP) on mean $F A$ in the seven tracts of interest: forceps minor, and three bilateral tracts: $A T R, C B$, UF. Group was the independent variable; age, sex, IQ, and handedness were covariates; and mean FA in the 7 tracts was the multiple dependent variables.

2.ii. Univariate analyses (seven parallel ANCOVAs; one for each tract of interest) were performed to identify which tract contributed to the main effect of group across all tracts of interest. Group and covariates were the independent variables, and mean FA in each tract was the dependent variable.

2.iii. Tractometry analyses [56] determined whether the main effects of group were focal or across the entire tract. To identify the specific nodes that contributed to the main effect of group, 98 parallel ANCOVAs (one for each node [see dMRI data analyses above] with group as the main independent variable) were performed for each tract showing a main effect of group in 2.ii. FDR correction $(q \leq 0.05)$ was performed across all such ANOCVAs for nodes in tracts showing the main effect of group in 2.ii. Cluster (s) comprising 10 or more nodes in each tract that showed a significant main effect of group in 2.ii were identified. FA was averaged across all nodes in the cluster (s) for further analyses in 3 below.

$R D$ and $A D$. To interpret the main between-group FA findings, mean RD and $A D$ were extracted from the same cluster (s) identified in 2.iii for further analyses.

\section{Between-group differences in clusters}

3.i. Pair-wise comparisons among $B D, O B P, O C P$, and $O H P$. To test our main hypotheses, 12 pair-wise comparisons ( 3 for each group: BD, OBP, OCP, $\mathrm{OHP}$ ) were performed to determine which specific between-group comparisons were driving the main effect of group in 2.iii. Here, pairwise comparisons were performed using FA in cluster (s) identified in 2.iii. Age, sex, IQ, and handedness were covariates. An FDR correction $(q<0.05)$ accounted for multiple comparisons.

3.ii. Pair-wise comparisons between $B D$, non- $B D O B P$ and $O C P$, healthy $O B P$ and $O C P$, and $O H P$. 12 pair-wise comparisons ( 3 for each group) were also performed to determine the extent to which having a non-BD diagnosis contributed to the effects in 3.i, using $q<0.05$.

3.iii. Converters. To further determine whether Converters resembled offspring with $\mathrm{BD}$ or other offspring groups, pair-wise $t$ tests explored differences between Converters and other groups (BD, OBP, OCP, OHP) in each cluster showing the main effect of group in 2.iii, using FDR $q<0.05$.

Exploratory analyses examined effects of medication, and relationships with symptom severity and other illness metrics (Supplementary Materials).

\section{RESULTS}

\section{Between-group differences in demographic and clinical} measures

There were no significant between-group differences in age, sex, handedness, and IQ (Table 1). SES was significantly higher in OHP versus OBP $(p<0.001)$. SES and IQ were correlated (rho $=0.356$, $p<0.001$ ); only IQ was thus selected as a covariate in main analyses. For findings using SES as a covariate, see Supplementary Materials.

\section{Main effect of group on FA in WM tracts of interest}

2.i. There was a significant main effect of group on mean FA across all tracts of interest $(F[21,262]=2.58, p<0.001$, Wilk's $\Lambda=0.583$, partial $\left.\eta^{2}=0.165\right)$.

2.ii. ANCOVAs revealed that there was a significant effect of group on mean FA in bilateral ATR and right CB (Table 2).

2.iii. Tractometry analyses. Four distinct clusters ( $q \leq 0.05$; in $>10$ consecutive nodes) were identified: in left ATR ( $k=24$ nodes in the proximity of the thalamus; $F=6.81 ; q=0.005)$, right ATR $(k=$ 16 nodes in the proximity of the thalamus; $F=6.86 ; p=0.004)$, and two clusters in right $\mathrm{CB}$ : anterior cluster $(k=12$ nodes; $F=$ $3.97, p=0.01)$, and middle cluster $(k=12$ nodes; $F=4.00 ; p=$ 0.01; Fig. 1).

\section{Between-group differences in clusters}

3.i. Pair-wise comparisons between $B D, O B P, O C P, O H P$. BD showed significantly lower $F A$ in the right $C B$ in both clusters than OBP (anterior $q=0.003$; middle $q=0.005$ ), and in the anterior cluster versus OCP $(q=0.024)$, and OHP $(q=0.024)$. BD showed significantly lower FA in the bilateral ATR clusters than OBP and OCP (left: $q<0.00$, right: $q<0.001$ ). OBP showed significantly higher FA in bilateral ATR clusters than OHP(left: $q=0.005$, right: $q<0.001)$. OBP also showed significantly higher $\mathrm{FA}$ in the middle cluster of the right CB than OHP $(q=0.003)$. OCP showed significantly higher FA in bilateral ATR clusters than OHP(left: $q=0.017$, right: $q=0.005$; Fig. 1). Effect sizes for all significant pair-wise comparisons were medium to large (Table 3).

Pair-wise $t$ tests examining between-group differences using mean RD for each cluster are in Supplementary Table 2. RD was higher in $\mathrm{BD}$ than OBP and OCP in most of the clusters. There were no between-group differences in AD.

3.ii. Pair-wise comparisons between, non-BD OBP and OCP $(n=$ 23), healthy $O B P$ and $O C P(n=29)$, and $O H P$. In all clusters, healthy OBP and OCP showed higher FA than BD. In bilateral ATR clusters and the middle cluster of the right $C B$, healthy, but not non- $B D$, OBP and OCP showed higher FA than OHP. In bilateral ATR clusters and the anterior cluster of the right $C B$, non-BD OBP and $O C P$ showed higher FA than $\mathrm{BD}$. FA was higher in healthy OBP and OCP versus non-BD OBP and OCP in the right ATR cluster(all $q \mathrm{~s}<0.05$; Fig. 2; Supplementary Table 3).

3.iii. Converters $(n=5)$. In the cluster in the right ATR (Supplementary Fig. 1), Converters showed lower FA than OBP. There was no difference between Converters and BD (Supplementary Table 4).

Effects of medication. Given that $16 / 21 \mathrm{BD}$, but very few OBP and $\mathrm{OCP}$, were medicated, exploratory analyses in all BD examined relationships between taking vs. not taking medication and FA 
Table 1. Demographic and clinical characteristics of children with bipolar disorder (BD); offspring of bipolar parents (OBP); offspring of comparison parents with non-BD psychopathology (OCP) and healthy offspring of healthy parents (OHP). In OBP and OCP, 23 participants had non-BD diagnoses and 29 were healthy.

\begin{tabular}{|c|c|c|c|c|c|c|}
\hline & $\mathrm{BD}^{\mathrm{a}}(n=21)$ & OBP $(n=25)$ & OCP $(n=27)$ & OHP $(n=32)$ & Statistic $\mathbf{c}^{\mathbf{b}, \mathbf{c}}$ & $p$ value \\
\hline Age at scan $(y)$, mean $\pm S D^{e}$ & $13.89 \pm 2.88$ & $13.59 \pm 2.49$ & $13.12 \pm 2.23$ & $13.19 \pm 2.57$ & $H[3]=2.275$ & 0.517 \\
\hline Female/male & $14 / 7$ & $12 / 13$ & $12 / 15$ & $14 / 18$ & $X^{2}[3]=3.197$ & 0.362 \\
\hline Right/left-handed & $21 / 0$ & $24 / 1$ & $26 / 1$ & $30 / 2$ & $X^{2}[3]=1.355$ & 0.716 \\
\hline Non-BD diagnosis yes/no & $19 / 2$ & $10 / 15$ & $13 / 14$ & $32 / 0$ & $X^{2}[2]=13.447$ & 0.001 \\
\hline $\mathrm{IQ}$, mean $\pm \mathrm{SD}$ & $103.10 \pm 14$ & $99.76 \pm 13.5$ & $101.11 \pm 12.1$ & $103.44 \pm 13.5$ & $H[3]=1.963$ & 0.580 \\
\hline Socioeconomic status ${ }^{\mathrm{f}}$, mean \pm SD & $3.48 \pm 1.3$ & $2.68 \pm 1.3$ & $3.33 \pm 1.4$ & $4.09 \pm 1.2$ & $H[3]=15.968$ & 0.001 \\
\hline SCARED—Child Version, mean \pm SD & $25.57 \pm 18.76$ & $14.20 \pm 16.07$ & $10.26 \pm 13.87$ & $7.81 \pm 7.46$ & $H[3]=15.771$ & $<0.001$ \\
\hline 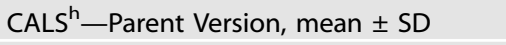 & $30.42 \pm 13.58$ & $8.11 \pm 10.39$ & $4.65 \pm 6.15$ & $2.34 \pm 2.95$ & $\mathrm{H}[3]=45.458$ & $<0.001$ \\
\hline CALS-Child Version, mean \pm SD & $28.43 \pm 16.2$ & $10.92 \pm 10.51$ & $7.85 \pm 11.18$ & $3.09 \pm 3.93$ & $\mathrm{H}[3]=37.850$ & $<0.001$ \\
\hline$M F Q^{i}-$ Parent Version, mean $\pm S D$ & $23.47 \pm 14.05$ & $5.79 \pm 7.75$ & $3.42 \pm 3.41$ & $1.90 \pm 3.60$ & $\mathrm{H}[3]=44.640$ & $<0.001$ \\
\hline MFQ—Child Version, mean \pm SD & $19.95 \pm 16.39$ & $8.28 \pm 8.32$ & $8.00 \pm 11.23$ & $2.94 \pm 4.28$ & $H[3]=23.564$ & $<0.001$ \\
\hline Offspring Behavioral disorder & 7 & 3 & 4 & 0 & & \\
\hline Offspring ADHD & 11 & 5 & 2 & 0 & & \\
\hline Parent (relative) Bipolar disorder & 21 & $B D-I=16 / B D-I I=9$ & 0 & 0 & & \\
\hline Parent Depressive spectrum disorders & 4 & 2 & 19 & 0 & & \\
\hline Parent Anxiety spectrum disorders & 7 & 21 & 19 & $0^{1}$ & & \\
\hline Parent Behavioral disorder & 3 & 18 & 4 & 0 & & \\
\hline Parent ADHD & 1 & 9 & 2 & 0 & & \\
\hline Parent Substance use disorders & 3 & 18 & 11 & 0 & & \\
\hline Parent Axis II disorders & 4 & 12 & 4 & 0 & & \\
\hline
\end{tabular}

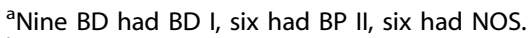

${ }^{\mathrm{b}}$ The $\mathrm{H}$ statistic refers to the Kruskal-Wallis test used to compare groups on non-normally distributed variables.

${ }^{\top}$ The $\mathrm{chi}^{2}$ statistic refers to the Chi-squared test used to compare groups on relative numbers of participants in specific categories.

$\mathrm{d}_{p}$ values $\leq 0.05$ are reported in bold characters.

${ }^{e} \mathrm{SD}=$ standard deviation.

${ }^{\mathrm{S}} \mathrm{SES}(1=08-19,2=20-29,3=30-39,4=40-54,5=55-66)$.

${ }^{9}$ SCARED $=$ Screen for Childhood Anxiety and Related Disorders (range, 0-82).

${ }^{\mathrm{h}}$ CALS $=$ Child Affect Lability Scale (range, 0-80).

${ }^{\mathrm{i}} \mathrm{MFQ}=$ Mood and Feelings Questionnaire (Parent version range, 0-68; Child version range, 0-66).

${ }^{\mathrm{j} K M R S}=\mathrm{K}-\mathrm{SADS}$ Mania Rating Scale (range, 0-64).

${ }^{k}$ KDRS $=$ K-SADS Depression Rating Scale (range, 0-61).

'Other than mild symptoms of anxiety disorders/PTSD.

As KMRS and KDRS were administered separately from the scan, regression analyses were performed between latency of KSADS ratings and FA in each of the four clusters showing a main effect of group. There was no significant effect of K-SADS latency on FA in each of these four clusters (Supplementary Materials).

Table 2. Effects of group on mean FA in each tract of interest.

\begin{tabular}{llrl|} 
Tract & $\boldsymbol{F}$ & $\boldsymbol{p}$ value & FDR corrected $\boldsymbol{q}$ value \\
\hline Forceps minor & 0.276 & 0.842 & 0.842 \\
\hline Left ATR & $\mathbf{5 . 6 9 2}$ & $\mathbf{0 . 0 0 1}$ & $\mathbf{0 . 0 0 4}$ \\
\hline Right ATR & $\mathbf{6 . 5 8 0}$ & $<\mathbf{0 . 0 0 1}$ & $\mathbf{0 . 0 0 3}$ \\
\hline Left CB & 2.521 & 0.062 & 0.102 \\
\hline Right CB & $\mathbf{4 . 8 0 3}$ & $\mathbf{0 . 0 0 4}$ & $\mathbf{0 . 0 0 9}$ \\
\hline Left UF & 2.393 & 0.073 & 0.102 \\
\hline Right UF & 1.844 & 0.144 & 0.168 \\
\hline
\end{tabular}

$q$ values $\leq 0.05$ are reported in bold characters.

ATR anterior thalamic radiation, $C B$ cingulum bundle, UF uncinate fasciculus. in all four clusters showing a main effect of group. These analyses revealed no significant main effect of medication (Supplementary Materials).

\section{DISCUSSION}

We used dMRI and tractometry to identify WM microstructural abnormalities distinguishing $B D$ offspring of $B D$ parents $(B D)$ from non-BD offspring of both $\mathrm{BD}$ and non-BD parents (OBP and OCP, respectively) and healthy offspring of healthy parents (OHP). In support of our first hypothesis, BD showed lower FA than OBP and OCP in four clusters in three WM tracts in emotional regulation and reward processing circuitries, including posterior portions of bilateral ATR, and anterior right $\mathrm{CB}$; and in a middle cluster in the 


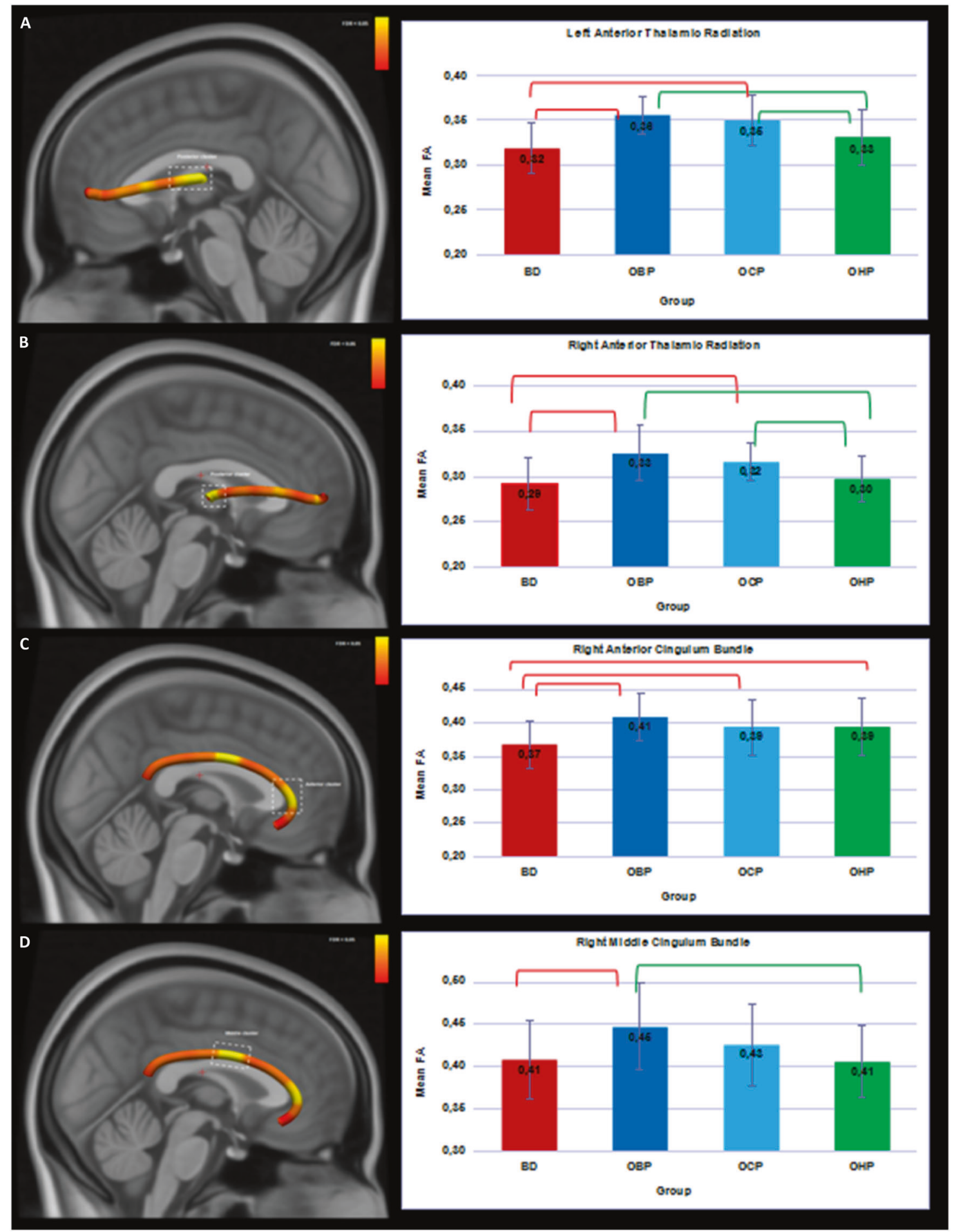

Fig. 1 3D visualization of the white matter tracts showing group differences across four groups (BD, OBP, OCP, and OHP). Bar plots represent the mean FA with the main effect of group (FDR-corrected) in four clusters. Red brackets show significant differences in BD versus other groups $(q<0.05)$. Green brackets show significant differences in OHP versus other groups $(q<0.05)$. Error bars represent standard deviations. BD—offspring with BD; OBP-offspring of bipolar parents; OCP-offspring of comparison parents; OHP - healthy offspring of healthy parents. A Left Anterior Thalamic Radiation. B Right Anterior Thalamic Radiation. C Anterior cluster of the Right Cingulum Bundle. D Middle cluster of the Right Cingulum Bundle.

right $\mathrm{CB}$ versus $\mathrm{OHP}$. Contrary to our second hypothesis, $\mathrm{OBP}$ and OCP showed higher bilateral ATR FA than OHP. Furthermore, and in support of our third hypothesis, healthy, but not non-BD, OBP and OCP showed higher middle right $C B$ and bilateral ATR FA than OHP. FA was higher in healthy OBP and OCP versus non-BD OBP and OCP in the right ATR cluster. Exploratory analyses revealed that Converters showed significantly lower FA in this right ATR cluster versus OBP and, at a trend level, versus OCP; and had FA in this cluster at a similar level to $\mathrm{BD}$ (slightly higher), rather than OBP and OCP who did not convert. 
Table 3. Between-group differences of FA for four groups (BD, OBP, OCP, and OHP)

\begin{tabular}{|c|c|c|c|c|c|c|c|}
\hline Tract & Nodes $^{\mathrm{b}}$ in cluster & Comparisons & Mean Diff. ${ }^{c}$ & $S^{d}$ & Cohen's $d$ & $p$ value & FDR corrected, $q$ value ${ }^{e}$ \\
\hline \multirow[t]{6}{*}{ Left ATR ${ }^{f}$} & $75-98$ & $\mathrm{BD}<\mathrm{OBP}$ & 0.038 & 0.008 & 1.43 & $<0.001$ & $<0.001$ \\
\hline & & $\mathrm{BD}<\mathrm{OCP}$ & 0.034 & 0.008 & 1.05 & $<0.001$ & $<0.001$ \\
\hline & & $\mathrm{BD}<\mathrm{OHP}$ & 0.015 & 0.008 & 0.40 & 0.056 & 0.096 \\
\hline & & $\mathrm{OBP}>\mathrm{OCP}$ & 0.004 & 0.007 & 0.25 & 0.562 & 0.613 \\
\hline & & $\mathrm{OBP}>\mathrm{OHP}$ & 0.023 & 0.007 & 0.91 & 0.002 & 0.005 \\
\hline & & $\mathrm{OCP}>\mathrm{OHP}$ & 0.019 & 0.007 & 0.61 & 0.008 & 0.017 \\
\hline \multirow{5}{*}{ Right ATR } & & $\mathrm{BD}<\mathrm{OCP}$ & 0.028 & 0.006 & 0.96 & $<0.001$ & $<0.001$ \\
\hline & & $\mathrm{BD}<\mathrm{OHP}$ & 0.010 & 0.006 & 0.22 & 0.130 & 0.184 \\
\hline & & $\mathrm{OBP}>\mathrm{OCP}$ & 0.007 & 0.006 & 0.80 & 0.275 & 0.314 \\
\hline & & $\mathrm{OBP}>\mathrm{OHP}$ & 0.025 & 0.006 & 1.01 & $<0.001$ & $<0.001$ \\
\hline & & $\mathrm{OCP}>\mathrm{OHP}$ & 0.018 & 0.006 & 0.38 & 0.002 & 0.005 \\
\hline \multirow{2}{*}{ Right $\mathrm{CB}^{\mathrm{g}}$} & & $\mathrm{OBP}>\mathrm{OHP}$ & 0.013 & 0.010 & 0.36 & 0.206 & 0.260 \\
\hline & & $\mathrm{OCP}>\mathrm{OHP}$ & 0.001 & 0.010 & 0.01 & 0.936 & 0.936 \\
\hline \multirow[t]{6}{*}{ Right CB } & $50-61$ & $\mathrm{BD}<\mathrm{OBP}$ & 0.041 & 0.013 & 0.79 & 0.002 & 0.005 \\
\hline & & $\mathrm{BD}<\mathrm{OCP}$ & 0.023 & 0.013 & 0.37 & 0.083 & 0.125 \\
\hline & & $\mathrm{BD}<\mathrm{OHP}$ & 0.002 & 0.013 & 0.05 & 0.860 & 0.897 \\
\hline & & $\mathrm{OBP}>\mathrm{OCP}$ & 0.018 & 0.012 & 0.43 & 0.141 & 0.188 \\
\hline & & OBP $>$ OHP & 0.038 & 0.012 & 0.89 & 0.001 & 0.003 \\
\hline & & $\mathrm{OCP}>\mathrm{OHP}$ & 0.021 & 0.011 & 0.44 & 0.076 & 0.122 \\
\hline \multicolumn{8}{|c|}{$\begin{array}{l}{ }^{a} \text { Group \#5 (Converters) had significantly lower FA } \\
{ }^{b} \text { Each tract divided into } 98 \text { nodes. } \\
{ }^{c} \text { Mean Diff = Mean Difference. } \\
{ }^{d} S E=\text { Standard Error. } \\
e^{{ }^{d}} q \text { values } \leq 0.05 \text { are reported in bold characters. } \\
{ }^{f} A T R=\text { anterior thalamic radiation. } \\
{ }^{9} \mathrm{CB}=\text { cingulum bundle. }\end{array}$} \\
\hline
\end{tabular}

BD showed significantly lower FA in bilateral ATR and in the anterior cluster of the right $\mathrm{CB}$, and higher $\mathrm{RD}$ in most clusters, than both at-risk groups, and significantly lower $F A$ in the anterior right $\mathrm{CB}$ cluster than $\mathrm{OHP}$, indicating reduced collinearity and/or lower integrity of fibers, and/or altered myelination [73], in these tracts in BD. FA was also significantly lower in the middle cluster of the right $C B$ in $B D$ versus $O B P$. Our findings are partially consistent with the existing literature, where youth with $B D$ showed lower $F A$ in the $C B$ relative to youth with a first-degree $B D$ relative $[38,81]$. Lower FA in the specific portions of bilateral ATR that we observed might contribute more to emotional dysregulation and aberrant reward processing because of their proximity to subcortical limbic structures involved in emotional regulation and reward processing. Other studies, however, did not report any differences in FA in the ATR in BD versus healthy OBP [82], in BD versus their healthy first-degree relatives [39], and in BD versus youth with a first-degree $B D$ relative $[32,38]$. Additionally, previous studies $[32,33,35-37,83,84]$ and a recent meta-analysis [30] reported significantly lower FA in BD than healthy controls in several tracts. Younger age of $\mathrm{BD}$ onset and longer $\mathrm{BD}$ duration was associated with higher FA in tracts showing between-group differences in FA (Supplementary Materials). These findings might reflect the fact that almost all $\mathrm{BD}$ were taking medication (mean duration $=2.48$ years), which might have had an ameliorative effect on FA $[85,86]$.

Contrary to our second hypothesis, bilateral ATR FA was higher in OBP and OCP than OHP, and FA in the middle cluster of the right $\mathrm{CB}$ was higher in $\mathrm{OBP}$ than OHP. Furthermore, in bilateral $A T R$ clusters and the middle cluster of the right $C B$, healthy, but not non-BD, OBP and OCP showed higher FA than OHP. Only one previous study compared OBP, OCP, and OHP [25]. Here, lower FA in OBP and OCP versus OHP was in left-sided tracts(including the $C B$, inferior longitudinal fasciculus, and forceps minor), but higher FA in OBP and OCP versus OHP was observed in right-sided tracts (including UF and inferior longitudinal fasciculus), paralleling our findings of higher FA in predominantly right-sided tracts in OBP and OCP versus OHP. These two studies employed different methodologies $[56,87,88]$, and the previous study included a larger number of OBP, OCP, and OHP: four OBP, five OCP, two OHP were excluded from the current study due to poor reconstruction using TractSeg. In the previous study, the four OBP and one OCP Converters were excluded. In the present study, Converters were included, and OBP and OCP had not converted to BD despite a mean follow-up period of 5.2 years post scan.

The ATR and CB support executive $[89,90]$ function and emotional regulation [91-93]. Thus, our findings of elevated FA in bilateral ATR in OBP and OCP, and in the right $C B$ in $O B P$, and the fact that this pattern of elevated $F A$ was evident only in healthy $\mathrm{OBP}$ and $\mathrm{OCP}$, suggest a compensatory rearrangement of the fibers in bilateral ATR to overcome familial predisposition to psychiatric disorders in general, and possibly in the right $C B$ to overcome familial predisposition to $B D[25,94]$. Indeed, elevated FA has been proposed as a compensatory mechanism 

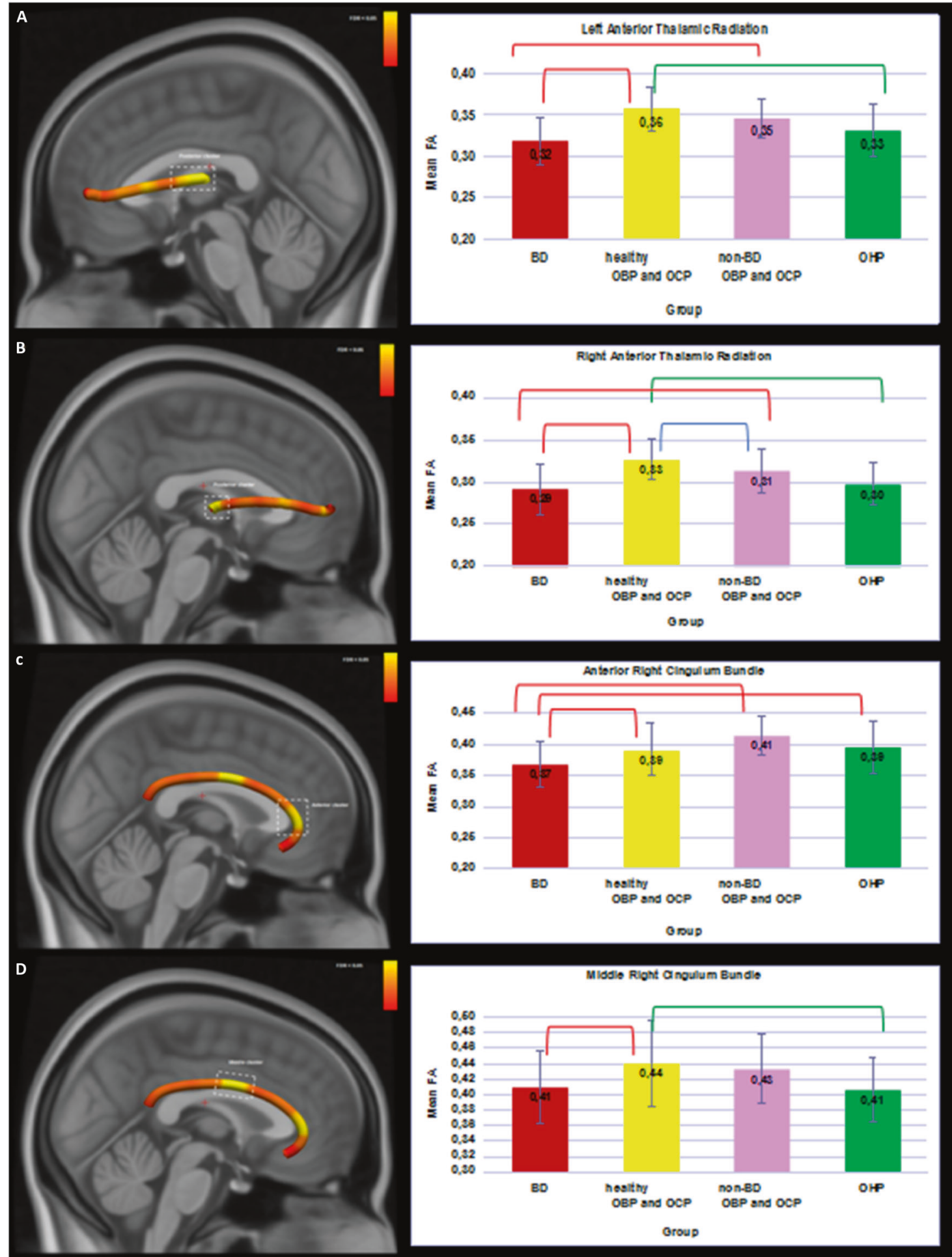

Fig. 2 3D visualization of the white matter tracts showing group differences across four groups (BD, healthy OBP and OCP, non-BD OBP and $\mathbf{O C P}$, and OHP). Bar plots represent the mean FA with the main effect of group (FDR-corrected) in 4 clusters. Red brackets show significant differences in BD versus other groups $(q<0.05)$. Green brackets show significant differences in OHP versus other groups $(q<0.05)$. Blue brackets show significant differences between healthy OBP and OCP and non-BD OBP and OCP. Error bars represent standard deviations. BD - offspring with BD; OBP-offspring of bipolar parents; OCP-offspring of comparison parents; OHP-healthy offspring of healthy parents. A Left Anterior Thalamic Radiation. B Right Anterior Thalamic Radiation. C Anterior cluster of the Right Cingulum Bundle. D Middle cluster of the Right Cingulum Bundle.

in neurodegenerative diseases [95], and elevated FA in motor tracts, a compensatory reorganization of WM fibers in Parkinson's disease, possibly reflecting adaptive or extended neuroplasticity [96].
Non-BD OBP and OCP had significantly lower FA in the right ATR cluster than healthy OBP and OCP, and did not show significant differences in FA in this cluster than OHP. Furthermore, despite a small sample size, our exploratory analyses revealed that 
Converters also had lower FA than OBP in the right ATR cluster. Alongside our findings above showing that elevated FA in right (and left) ATR might protect against psychiatric disorders, these findings suggest that absence of elevated right ATR FA might result in lack of protection against future $B D$ in OBP and OCP. By contrast, low anterior right $C B$ FA might represent a neural correlate of having $\mathrm{BD}$, given that this was the only tract in which BD showed significantly lower FA than OHP. Together, these data highlight a potential role of the right hemisphere in protective mechanisms against behaviors related to dysregulation and $B D$, depending upon the magnitude of structural, and potentially, functional measures in circuitries supporting emotional regulation and reward processing. Indeed, greater activity in the right prefrontal cortex has been shown to be associated with greater risk aversion [97]. Our findings also parallel reports highlighting how diffusivity measures in the $\mathrm{CB}$ might predict resilience and impulsiveness in BD at-risk youth [98], and provide potential neural targets for early interventions in at-risk youth $[99,100]$.

Certain limitations should be considered. Although effect sizes in the present study are medium to large, future studies with larger samples sizes should aim to replicate these findings, especially abnormally elevated FA in OBP and OCP in bilateral ATR. Our subgroup of converters was small, although this sample, which was $\sim 10 \%$ of the size of combined OBP and OCP, is similar to reported conversion rates in OBP and OCP [9-11]. Converters were $\sim 2$ years older than other groups, indicating the need for longer follow-up in order to include a larger number of Converters in future studies. While most of our mood-related measures were assessed on the day of the scan, the KMRS and KDRS were assessed on average within two months before or after the scan day. Regression analyses examining relationships between the latency of the KMRS and KDRS ratings and FA in clusters showing a main effect of group revealed no significant effects, however (Supplementary Materials). The novel tractometry approach used to examine WM tracts differed from that used in our previous study [23], with differences, although some similarities, in findings between the two studies. The majority of BD was medicated, but only three OCP and two OB, were medicated. Exploratory analyses did not reveal any effect of taking medication on FA in any of the four clusters in BD, however (Supplementary Materials).

This is the first dMRI study comparing offspring with $B D$ and offspring at risk for BD and/or other psychopathology with prospective follow-up, allowing comparison of those who converted to BD with those who did not do so. We highlight a potential role of dMRI in identifying objective biomarkers that might reflect underlying neural mechanisms that predispose to versus protecting against future $\mathrm{BD}$ and non-BD psychopathology, to help identify youth most at risk of future BD.

\section{Funding and disclosure}

The present study was supported by the National Institute of Mental Health grant R01 MH060952-16 (MPIs: Boris Birmaher and Mary L. Phillips), and by the Pittsburgh Foundation (Mary L. Phillips). These funding institutions were not involved in the design or conduct of the study, the collection, management, analysis, or interpretation of the data, or the preparation, review, or approval of the manuscript.

Renata Rozovsky, Amelia Versace, Michele Bertocci, Cecile D. Ladouceur, Mary L. Phillips and Lisa K. Bonar, Kelly Monk, Halimah Abdul-Waalee, and Genna Bebko do not have any financial disclosures. Jay Fournier receives royalties from Guilford Press and has served as a paid consultant to Happify.com. Danella Hafeman receives funding from the Brain and Behavior Research Foundation. Boris Birmaher has or will receive royalties for publications from: Random House, Inc. (New Hope for Children and Teens with Bipolar Disorder), Lippincott Williams \& Wilkins (Treating Child and Adolescent Depression), Wolters Kluwer. Tina Goldstein receives royalties from Guilford Press. Dara Sakolsky received an honorarium from Northwell Health in 2018.

\section{REFERENCES}

1. Chang K, Howe M, Gallelli K, Miklowitz D. Prevention of pediatric bipolar disorder: integration of neurobiological and psychosocial processes. Ann NY Acad Sci. 2006;1094:235-47. Dec.

2. Merikangas KR, Akiskal HS, Angst J, Greenberg PE, Hirschfeld RM, Petukhova M, et al. Lifetime and 12-month prevalence of bipolar spectrum disorder in the national comorbidity survey replication. Arch Gen Psychiatry. 2007;64:543-52. May.

3. Leibenluft E, Rich BA. Pediatric bipolar disorder. Annu Rev Clin Psychol. 2008;4:163-87.

4. DelBello MP, Geller B. Review of studies of child and adolescent offspring of bipolar parents. Bipolar Disord. 2001;3:325-34.

5. Pavuluri MN, Birmaher B, Naylor MW. Pediatric bipolar disorder: a review of the past 10 years. J Am Acad Child Adolesc Psychiatry. 2005;44:846-71. Sep.

6. Sucksdorff D, Chudal R, Suominen A, Jokiranta E, Brown AS, Sourander A. Bipolar disorder and parental psychopathology. Soc Psychiatry Psychiatr Epidemiol. 2014;49:1973-84. Dec.

7. Axelson D, Goldstein B, Goldstein T, Monk K, Yu H, Hickey MB, et al. Diagnostic precursors to bipolar disorder in offspring of parents with bipolar disorder: a longitudinal study. Am J Psychiatry. 2015;172:638-46. Jul.

8. Bowden CL. A different depression: clinical distinctions between bipolar and unipolar depression. J Affect Disord. 2005;84:117-25. Feb.

9. Duffy A, Vandeleur C, Heffer N, Preisig M. The clinical trajectory of emerging bipolar disorder among the high-risk offspring of bipolar parents: current understanding and future considerations. Int J Bipolar Disord. 2017;5:37. Nov 22.

10. Birmaher B, Axelson D, Monk K, Kalas C, Goldstein B, Hickey MB, et al. Lifetime psychiatric disorders in school-aged offspring of parents with bipolar disorder: the Pittsburgh Bipolar Offspring study. Arch Gen Psychiatry. 2009;66:287-96. Mar.

11. Hafeman DM, Merranko J, Axelson D, Goldstein BI, Goldstein T, Monk K, et al. Toward the definition of a bipolar prodrome: dimensional predictors of bipolar spectrum disorders in at-risk youths. Am J Psychiatry. 2016;173:695-704. 01.

12. Hafeman DM, Merranko J, Goldstein TR, Axelson D, Goldstein BI, Monk K, et al. Assessment of a person-level risk calculator to predict new-onset bipolar spectrum disorder in youth at familial risk. JAMA Psychiatry. 2017;74:841-7. Aug 1.

13. Birmaher B, Axelson D, Goldstein B, Strober M, Gill MK, Hunt J, et al. Four-year longitudinal course of children and adolescents with bipolar spectrum disorders: the Course and Outcome of Bipolar Youth (COBY) study. Am J Psychiatry. 2009;166:795-804. Jul.

14. Todd RD, Reich W, Petti TA, Joshi P, DePaulo JR JR, Nurnberger J, et al. Psychiatric diagnoses in the child and adolescent members of extended families identified through adult bipolar affective disorder probands. J Am Acad Child Adolesc Psychiatry. 1996;35:664-71. May.

15. Goodwin FK, Jamison KR. Manic-depressive illness: bipolar disorders and recurrent depression. Vol. 1, 2nd edition. Oxford University Press; 2007. p. 736.

16. Linke J, Witt SH, King AV, Nieratschker V, Poupon C, Gass A, et al. Genome-wide supported risk variant for bipolar disorder alters anatomical connectivity in the human brain. Neurolmage 2012;59:3288-96. Feb 15.

17. Phillips $M$, Ladouceur C, Drevets W. A neural model of voluntary and automatic emotion regulation: implications for understanding the pathophysiology and neurodevelopment of bipolar disorder. Mol Psychiatry. 2008;13:829-57. Sep.

18. Reichart CG, Wals M, Hillegers MHJ, Ormel J, Nolen WA, Verhulst FC. Psychopathology in the adolescent offspring of bipolar parents. J Affect Disord. 2004;78:67-71. Jan 1.

19. Goldstein BI, Shamseddeen W, Axelson DA, Kalas C, Monk K, Brent DA, et al. Clinical, demographic, and familial correlates of bipolar spectrum disorders among offspring of parents with bipolar disorder. J Am Acad Child Adolesc Psychiatry. 2010;49:388-96. Apr.

20. Chang K, Steiner H, Dienes K, Adleman N, Ketter T. Bipolar offspring: a window into bipolar disorder evolution. Biol Psychiatry. 2003;53:945-51. Jun 1.

21. Wals M, Hillegers MH, Reichart CG, Ormel J, Nolen WA, Verhulst FC. Prevalence of psychopathology in children of a bipolar parent. J Am Acad Child Adolesc Psychiatry. 2001;40:1094-102. Sep.

22. Mordoch E, Hall WA. Children living with a parent who has a mental illness: a critical analysis of the literature and research implications. Arch Psychiatr Nurs. 2002;16:208-16. Oct.

23. Homlong L, Rosvold EO, Sagatun $\AA$, Wentzel-Larsen T, Haavet OR. Living with mentally ill parents during adolescence: a risk factor for future welfare dependence? A longitudinal, population-based study. BMC Public Health. 2015;15:413. https://doi.org/10.1186/s12889-015-1734-1.

24. Yamamoto R, Keogh B. Children's experiences of living with a parent with mental illness: a systematic review of qualitative studies using thematic analysis. J Psychiatr Ment Health Nurs. 2018;25:131-41. Mar. 
25. Versace A, Ladouceur CD, Graur S, Acuff HE, Bonar LK, Monk K, et al. Diffusion imaging markers of bipolar versus general psychopathology risk in youth at-risk. Neuropsychopharmacology. 2018;43:2212-20. Oct.

26. Acuff HE, Versace A, Bertocci MA, Hanford LC, Ladouceur CD, Manelis A, et al. White matter - emotion processing activity relationships in youth offspring of bipolar parents. J Affect Disord. 2019;243:153-64. Jan 15.

27. Bellani M, Boschello F, Delvecchio G, Dusi N, Altamura CA, Ruggeri M, et al. DTI and Myelin Plasticity in Bipolar Disorder: Integrating Neuroimaging and Neuropathological Findings. Front Psychiatry. 2016;7:21.

28. Phillips ML, Swartz HA. A critical appraisal of neuroimaging studies of bipolar disorder: toward a new conceptualization of underlying neural circuitry and roadmap for future research. Am J Psychiatry. 2014;171:829-43. Aug 1.

29. Mahon K, Burdick KE, Szeszko PR. A role for white matter abnormalities in the pathophysiology of bipolar disorder. Neurosci Biobehav Rev. 2010;34:533-54. Mar.

30. Hu R, Stavish C, Leibenluft E, Linke JO. White matter microstructure in individuals with and at risk for bipolar disorder: evidence for an endophenotype from a voxel-based meta-analysis. Biol Psychiatry Cogn Neurosci Neuroimaging. 2020;5:1104-13. Dec 1.

31. Koshiyama D, Fukunaga M, Okada N, Morita K, Nemoto K, Usui K, et al. White matter microstructural alterations across four major psychiatric disorders: megaanalysis study in 2937 individuals. Mol Psychiatry. 2020;25:883-95. Apr.

32. Linke JO, Stavish C, Adleman NE, Sarlls J, Towbin KE, Leibenluft E, et al. White matter microstructure in youth with and at risk for bipolar disorder. Bipolar Disord. 2020;22:163-73. Mar.

33. Favre $P$, Pauling $M$, Stout J, Hozer F, Sarrazin S, Abé $C$, et al. Widespread white matter microstructural abnormalities in bipolar disorder: evidence from megaand meta-analyses across 3033 individuals. Neuropsychopharmacology. 2019;44: 2285-93. Dec.

34. Versace A, Andreazza AC, Young LT, Fournier JC, Almeida JR, Stiffler RS, et al. Elevated serum measures of lipid peroxidation and abnormal prefrontal white matter in euthymic bipolar adults: toward peripheral biomarkers of bipolar disorder. Mol Psychiatry. 2014;19:200-8. Feb.

35. Wang F, Jackowski M, Kalmar JH, Chepenik LG, Tie K, Qiu M, et al. Abnormal anterior cingulum integrity in bipolar disorder determined through diffusion tensor imaging. Br J Psychiatry. 2008;193:126-9. Aug.

36. Sarrazin S, Poupon C, Linke J, Wessa M, Phillips M, Delavest M, et al. A multicenter tractography study of deep white matter tracts in bipolar I disorder: psychotic features and interhemispheric disconnectivity. JAMA Psychiatry. 2014;71:388-96. Apr.

37. Benedetti F, Yeh P-H, Bellani M, Radaelli D, Nicoletti MA, Poletti S, et al. Disruption of white matter integrity in bipolar depression as a possible structural marker of illness. Biol Psychiatry. 2011;69:309-17. Feb 15.

38. Mahapatra A, Khandelwal SK, Sharan P, Garg A, Mishra NK. Diffusion tensor imaging tractography study in bipolar disorder patients compared to first-degree relatives and healthy controls. Psychiatry Clin Neurosci. 2017;71:706-15. Oct.

39. Chaddock CA, Barker GJ, Marshall N, Schulze K, Hall MH, Fern A, et al. White matter microstructural impairments and genetic liability to familial bipolar I disorder. Br J Psychiatry. 2009;194:527-34. Jun.

40. Haller S, Xekardaki A, Delaloye C, Canuto A, Lövblad KO, Gold G, et al Combined analysis of grey matter voxel-based morphometry and white matter tract-based spatial statistics in late-life bipolar disorder. J Psychiatry Neurosci. 2011;36:391-401. Nov

41. Versace A, Almeida JR, Hassel S, Walsh ND, Novelli M, Klein CR, et al. Elevated left and reduced right orbitomedial prefrontal fractional anisotropy in adults with bipolar disorder revealed by tract-based spatial statistics. Arch Gen Psychiatry. 2008;65:1041-52. Sep.

42. Linke J, King AV, Poupon C, Hennerici MG, Gass A, Wessa M. Impaired anatomical connectivity and related executive functions: differentiating vulnerability and disease marker in bipolar disorder. Biol Psychiatry. 2013;74:908-16. Dec 15.

43. Chan W-Y, Yang G-L, Chia M-Y, Woon P-S, Lee J, Keefe R, et al. Cortical and subcortical white matter abnormalities in adults with remitted first-episode mania revealed by Tract-Based Spatial Statistics. Bipolar Disord. 2010;12:383-9. Jun.

44. Nortje G, Stein DJ, Radua J, Mataix-Cols D, Horn N. Systematic review and voxelbased meta-analysis of diffusion tensor imaging studies in bipolar disorder. J Affect Disord. 2013;150:192-200. Sep 5.

45. Ji E, Lejuste F, Sarrazin S, Houenou J. From the microscope to the magnet: disconnection in schizophrenia and bipolar disorder. Neurosci Biobehav Rev. 2019;98:47-57.

46. McDonald C, Bullmore ET, Sham PC, Chitnis X, Wickham H, Bramon E, et al. Association of genetic risks for schizophrenia and bipolar disorder with specific and generic brain structural endophenotypes. Arch Gen Psychiatry. 2004;61:974-84. Oct 1 .

47. Lee $D-K$, Lee $H$, Park K, Joh E, Kim C-E, Ryu S. Common gray and white matter abnormalities in schizophrenia and bipolar disorder. PLOS One. 2020;15: e0232826. Jul 5 .
48. Ren S, Chang M, Yin Z, Feng R, Wei Y, Duan J, et al. Age-related alterations of white matter integrity in adolescents and young adults with bipolar disorder. Front Psychiatry. 2019;10:1010.

49. Masuda Y, Okada G, Takamura M, Shibasaki C, Yoshino A, Yokoyama S, et al. White matter abnormalities and cognitive function in euthymic patients with bipolar disorder and major depressive disorder. Brain Behav. 2020;10:e01868. Dec.

50. Radoeva PD, Jenkins GA, Schettini E, Gilbert AC, Barthelemy CM, DeYoung LLA, et al. White matter correlates of cognitive flexibility in youth with bipolar disorder and typically developing children and adolescents. Psychiatry Res Neuroimaging. 2020;305:111169. Nov 30.

51. Ganzola R, Nickson T, Bastin ME, Giles S, Macdonald A, Sussmann J, et al. Longitudinal differences in white matter integrity in youth at high familial risk for bipolar disorder. Bipolar Disord. 2017;19:158-67.

52. Ganzola R, Mclntosh AM, Nickson T, Sprooten E, Bastin ME, Giles S, et al. Diffusion tensor imaging correlates of early markers of depression in youth at highfamilial risk for bipolar disorder. J Child Psychol Psychiatry. 2018;59:917-27.

53. Sprooten E, Sussmann JE, Clugston A, Peel A, McKirdy J, Moorhead TW, et al. White matter integrity in individuals at high genetic risk of bipolar disorder. Biol Psychiatry. 2011;70:350-6. Aug 15.

54. Versace A, Ladouceur CD, Romero S, Birmaher B, Axelson DA, Kupfer DJ, et al. Altered development of white matter in youth at high familial risk for bipolar disorder: a diffusion tensor imaging study. J Am Acad Child Adolesc Psychiatry. 2010;49:1249-59. Dec12. 59.e1.

55. Bora E, Can G, Zorlu N, Ulas G, Inal N, Ozerdem A. Structural dysconnectivity in offspring of individuals with bipolar disorder: the effect of co-existing clinicalhigh-risk for bipolar disorder. J Affect Disord. 2021;281:109-16. Feb 15

56. Wasserthal J, Neher $\mathrm{P}$, Maier-Hein $\mathrm{KH}$, TractSeg -. Fast and accurate white matter tract segmentation. Neurolmage 2018;183:239-53. Dec 1.

57. First MB, Gibbon ML, Spitzer RL, Williams JBW, Benjamin L. Structured clinical interview for DSM-IV axis I disorders-Non-patient edition (SCID-I/NP, Version 2.0). Biometrics Research Department, New York State Psychiatric Institute, New York.

58. Kaufman J, Birmaher B, Brent D, Rao U, Flynn C, Moreci P. et al.Schedule for affective disorders and schizophrenia for school-age children-present and lifetime version (K-SADS-PL, initial reliability and validity data.J Am Acad Child Adolesc Psychiatry.1997;36:980-8.

59. First MB, Gibbon ML, Spitzer RL, Williams JBW, Benjamin L. Structured clinical interview for DSM-IV axis II personality disorders (SCID-II). Washington, DC: American Psychiatric Press; 1997.

60. Weissman MM, Wickramaratne $P$, Adams $P$, Wolk S, Verdeli $H$, Olfson M. Brief screening for family psychiatric history: the family history screen. Arch Gen Psychiatry. 2000;57:675-82. Jul.

61. Birmaher B, Brent DA, Chiappetta L, Bridge J, Monga S, Baugher M.Psychometric properties of the Screen for Child Anxiety Related Emotional Disorders (SCARED, a replication study.J Am Acad Child Adolesc Psychiatry.1999;38:1230-6.

62. Birmaher B, Khetarpal S, Brent D, Cully M, Balach L, Kaufman J, et al.The Screen for Child Anxiety Related Emotional Disorders (SCARED, scale construction and psychometric characteristics.J Am Acad Child Adolesc Psychiatry.1997;36:545-53.

63. Gerson AC, Gerring JP, Freund L, Joshi PT, Capozzoli J, Brady K, et al. The Children's Affective Lability Scale: a psychometric evaluation of reliability. Psychiatry Res. 1996;65:189-98. Dec 20.

64. Sund AM, Larsson B, Wichstrom L. Depressive symptoms among young Norwegian adolescents as measured by the Mood and Feelings Questionnaire (MFQ). Eur Child Adolesc Psychiatry. 2001;10:222-9. Dec.

65. Axelson D, Birmaher BJ, Brent D, Wassick S, Hoover C, Bridge J, et al. A preliminary study of the Kiddie Schedule for Affective Disorders and Schizophrenia for School-Age Children mania rating scale for children and adolescents. J Child Adolesc Psychopharmacol. 2003;13:463-70.

66. Annett M. A classification of hand preference by association analysis. Br J Psychol. 1970;3:303-21. Aug;61.

67. Hollingshead A. Four-factor index of social status. New Haven, CT: Yale University; 1975.

68. Jenkinson $M$, Bannister $P$, Brady $M$, Smith $S$. Improved optimization for the robust and accurate linear registration and motion correction of brain images. Neurolmage. 2002;17:825-41. Oct.

69. Smith SM. Fast robust automated brain extraction. Hum Brain Mapp. 2002;17: 143-55. Nov.

70. Smith SM, Jenkinson M, Woolrich MW, Beckmann CF, Behrens TE, Johansen-Berg $\mathrm{H}$, et al. Advances in functional and structural MR image analysis and implementation as FSL. Neurolmage. 2004;23:S208-219.

71. Tournier J-D, Smith R, Raffelt D, Tabbara R, Dhollander $T$, Pietsch $M$, et al. MRtrix3: a fast, flexible and open software framework for medical image processing and visualisation. Neurolmage. 2019;202:116137. Nov 15.

72. Wasserthal J, Neher PF, Maier-Hein KH. Tract Orientation Mapping for Bundle-Specific Tractography. In: Frangi A, Schnabel J, Davatzikos C, AlberolaLópez C, Fichtinger G, editors. Medical Image Computing and Computer 
Assisted Intervention - MICCAI 2018. MICCAI 2018. Lecture Notes in Computer Science, vol 11072. Springer, Cham; 2018. https://doi.org/10.1007/978-3-03000931-1_5.

73. Jones DK, Leemans A. Diffusion tensor imaging. Methods Mol Biol. 2011;711: $127-44$.

74. Kochunov $\mathrm{P}$, Williamson DE, Lancaster J, Fox P, Cornell J, Blangero J, et al. Fractional anisotropy of water diffusion in cerebral white matter across the lifespan. Neurobiol Aging. 2012;33:9-20. Jan.

75. Lebel C, Gee M, Camicioli R, Wieler M, Martin W, Beaulieu C. Diffusion tensor imaging of white matter tract evolution over the lifespan. Neurolmage. 2012;60:340-52. Mar.

76. Simmonds D, Hallquist MN, Asato M, Luna B. Developmental stages and sex differences of white matter and behavioral development through adolescence: a longitudinal diffusion tensor imaging (DTI) study. Neurolmage. 2014;92:356-68. May 15.

77. Bathelt J, Scerif G, Nobre AC, Astle DE. Whole-brain white matter organization. Intell, Educ Attain Trends Neurosci Educ. 2019;15:38-47. Jun 1.

78. Holleran L, Kelly S, Alloza C, Agartz I, Andreassen OA, Arango C, et al. The relationship between white matter microstructure and general cognitive ability in patients with schizophrenia and healthy participants in the ENIGMA consortium. Am J Psychiatry. 2020;177:537-47. Mar 26.

79. Benjamini $Y$, Hochberg Y. Controlling the false discovery rate: a practical and powerful approach to multiple testing. J R Stat Soc Ser B Methodol. 1995;57: 289-300.

80. Wechsler D. Wechsler abbreviated scale of intelligence. San Antonio, TX: The Psychological Corporation; 1999.

81. Frazier JA, Breeze JL, Papadimitriou G, Kennedy DN, Hodge SM, Moore CM, et al. White matter abnormalities in children with and at risk for bipolar disorder. Bipolar Disord. 2007;9:799-809. Dec.

82. Besenek M, Yilmaz IT, Guleryuz H, Guney SA, Inal, Emiroglu N. Anterior cingulate cortex disconnectivity in high-risk offspring of bipolar patients: a preliminary DTI study. Dusunen Adam J Psychiatry Neurol Sci. 2019;32:203.

83. Niida R, Yamagata B, Niida A, Uechi A, Matsuda H, Mimura M. Aberrant anterior thalamic radiation structure in bipolar disorder: a diffusion tensor tractography study. Front Psychiatry. 2018;9:522. Oct 24.

84. Zhang S, Wang Y, Deng F, Zhong S, Chen L, Luo X, et al. Disruption of superficial white matter in the emotion regulation network in bipolar disorder. NeuroImage Clin. 2018;20:875-82.

85. Hafeman DM, Chang KD, Garrett AS, Sanders EM, Phillips ML. Effects of medication on neuroimaging findings in bipolar disorder: an updated review. Bipolar Disord. 2012;14:375-410. Jun.

86. Benedetti F, Absinta M, Rocca MA, Radaelli D, Poletti S, Bernasconi A, et al. Tractspecific white matter structural disruption in patients with bipolar disorder. Bipolar Disord. 2011;13:414-24. Jun.

87. Yendiki A, Panneck P, Srinivasan P, Stevens A, Zöllei L, Augustinack J, et al. Automated probabilistic reconstruction of white-matter pathways in health and disease using an atlas of the underlying anatomy. Front Neuroinform. 2011;5:23.

88. Wasserthal J, Neher PF, Hirjak D, Maier-Hein KH. Combined tract segmentation and orientation mapping for bundle-specific tractography. Med Image Anal. 2019;58:101559. Dec 1.

89. Van Der Werf YD, Jolles J, Witter MP, Uylings HBM. Contributions of thalamic nuclei to declarative memory functioning. Cortex. 2003;39:1047-62. Jan 1.

90. Mamah D, Conturo TE, Harms MP, Akbudak E, Wang L, McMichael AR, et al. Anterior thalamic radiation integrity in schizophrenia: a diffusion-tensor imaging study. Psychiatry Res. 2010;183:144-50.

91. Coenen VA, Panksepp J, Hurwitz TA, Urbach H, Mädler B. Human medial forebrain bundle (MFB) and anterior thalamic radiation (ATR): imaging of two major subcortical pathways and the dynamic balance of opposite affects in understanding depression. J Neuropsychiatry Clin Neurosci. 2012;24:223-36. Apr 1.

92. Torso M, Serra L, Giulietti G, Spanò B, Tuzzi E, Koch G, et al. Strategic lesions in the anterior thalamic radiation and apathy in early Alzheimer's disease. PLOS One. 2015;10:e0124998. May 1.

93. Deng $F$, Wang $Y$, Huang $H$, Niu M, Zhong S, Zhao L, et al. Abnormal segments of right uncinate fasciculus and left anterior thalamic radiation in major and bipolar depression. Prog Neuropsychopharmacol Biol Psychiatry. 2018;81:340-9. Feb 2.

94. Emsell L, Leemans A, Langan C, Van Hecke W, Barker GJ, McCarthy P, et al. Limbic and callosal white matter changes in euthymic bipolar I disorder: an advanced diffusion magnetic resonance imaging tractography study. Biol Psychiatry. 2013; 73:194-201. Jan 15.
95. Gregory S, Long Jeffrey D, Tabrizi SJ, Rees G. Measuring compensation in neurodegeneration using MRI. Curr Opin Neurol. 2017;30:380-7. Aug.

96. Mole JP, Subramanian L, Bracht T, Morris H, Metzler-Baddeley C, Linden DEJ. Increased fractional anisotropy in the motor tracts of Parkinson's disease suggests compensatory neuroplasticity or selective neurodegeneration. Eur Radio. 2016;26:3327-35.

97. Gianotti LR, Knoch D, Faber PL, Lehmann D, Pascual-Marqui RD, Diezi C, et al. Tonic activity level in the right prefrontal cortex predicts individuals' risk taking. Psychol Sci. 2009;20:33-8. Jan 1.

98. Koc D, Besenek M, Ulas G, Ildı A, Yilmaz IT, Guleryuz H, et al. Investigation of structure-function correlation among the young offspring of patients with bipolar disorder. Psychiatry Res Neuroimaging. 2020;301:111103. Jul 30.

99. Howes OD, Falkenberg I. Early detection and intervention in bipolar affective disorder: targeting the development of the disorder. Curr Psychiatry Rep. 2011;13:493-9.

100. Myczkowski ML, Fernandes A, Moreno M, Valiengo L, Lafer B, Moreno RA, et al. Cognitive outcomes of TMS treatment in bipolar depression: Safety data from a randomized controlled trial. J Affect Disord. 2018;235:20-6. Aug 1.

\section{ACKNOWLEDGEMENTS}

We would like to acknowledge the participants and their families for their contributions to this study.

\section{AUTHOR CONTRIBUTIONS}

Substantial contributions to the conception or design of the work; or the acquisition, analysis, or interpretation of data for the work-RR, AV, MP, LB, KM, HA, BB. Drafting the work or revising it critically for important intellectual content-RR, $A V, M P, B B, J F$, $L B, C L$. Final approval of the version to be published-RR, $A V, M P, M B, L B, C L, B B, J F$, $\mathrm{KM}, \mathrm{HA}, \mathrm{GB}, \mathrm{DH}, \mathrm{DS}$, TG. Agreement to be accountable for all aspects of the work in ensuring that questions related to the accuracy or integrity of any part of the work are appropriately investigated and resolved-RR, AV, MP.

\section{COMPETING INTERESTS}

The authors declare no competing interests.

\section{ADDITIONAL INFORMATION}

Supplementary information The online version contains supplementary material available at https://doi.org/10.1038/s41386-021-01088-1.

Correspondence and requests for materials should be addressed to R.R

Reprints and permission information is available at http://www.nature.com/ reprints

Publisher's note Springer Nature remains neutral with regard to jurisdictional claims in published maps and institutional affiliations.

Open Access This article is licensed under a Creative Commons Attribution 4.0 International License, which permits use, sharing, adaptation, distribution and reproduction in any medium or format, as long as you give appropriate credit to the original author(s) and the source, provide a link to the Creative Commons license, and indicate if changes were made. The images or other third party material in this article are included in the article's Creative Commons license, unless indicated otherwise in a credit line to the material. If material is not included in the article's Creative Commons license and your intended use is not permitted by statutory regulation or exceeds the permitted use, you will need to obtain permission directly from the copyright holder. To view a copy of this license, visit http://creativecommons. org/licenses/by/4.0/.

(c) The Author(s) 2021 